Research Paper

\title{
Efficacy and Safety of Thalidomide for Chemotherapy-induced Nausea and Vomiting
}

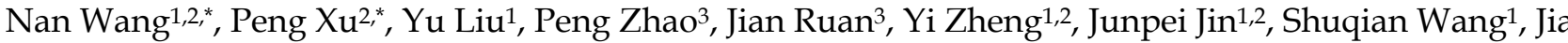 \\ $\mathrm{Yao}^{1}$, Dong Xiang ${ }^{4}$, Dai Zhang ${ }^{2}, \mathrm{Na} \mathrm{Li}^{1,2}$, Huafeng Kang ${ }^{2}$, and Zhijun Dai ${ }^{\circledR}$ \\ 1. Department of Breast Surgery, The First Affiliated Hospital, College of Medicine, Zhejiang University, Hangzhou, China. \\ 2. Department of Oncology, The Second Affiliated Hospital of Xi' an Jiaotong University, Xi'an, China. \\ 3. Department of Medical Oncology, The First Affiliated Hospital, College of Medicine, Zhejiang University, Hangzhou, China. \\ 4. Celilo Cancer Center, Oregon Health Science Center affiliated Mid-Columbia medical center, The Dalles, OR, USA. \\ *NW and PX contributed equally to this work.
}

$\triangle$ Corresponding authors: Zhijun Dai, Department of Breast Surgery, The First Affiliated Hospital, College of Medicine, Zhejiang University, Hangzhou 310003, China (E-Mail: dzj0911@126.com); or Huafeng kang, Department of Oncology, The Second Affiliated Hospital of Xi'an Jiaotong University, Xi'an, China (E-Mail: kanghuafeng1973@126.com).

(1) The author(s). This is an open access article distributed under the terms of the Creative Commons Attribution License (https://creativecommons.org/licenses/by/4.0/). See http://ivyspring.com/terms for full terms and conditions.

Received: 2020.03.05; Accepted: 2020.04.27; Published: 2020.05.18

\begin{abstract}
Purpose: A substantial number of cancer patients discontinue chemotherapy due to severe chemotherapy-induced nausea and vomiting (CINV). This study aimed to evaluate the efficacy and safety of thalidomide (THD) in CINV.

Methods: We searched different databases to identify related studies that investigated the efficacy and safety of THD in CINV. The primary outcomes were CINV in the acute ( $0-24 \mathrm{~h}$ ), delayed (24-120 h), and overall ( $0-120 \mathrm{~h})$ phases, respectively. The secondary outcomes were the safety of THD and the patients' quality of life (QOL).

Results: Fourteen randomized control trials (RCTs) including 1744 patients $(42 \%$ male) reported the risk ratio (RR) and $95 \% \mathrm{Cl}$ of the THD group versus control group in reducing nausea and vomiting. Meta-analysis showed that THD statistically enhanced the complete response rate of nausea and vomiting in the delayed (nausea: $\mathrm{RR}=1.69,95 \% \mathrm{Cl}: 1.47-1.94$; vomiting: $\mathrm{RR}=1.38,95 \% \mathrm{Cl}: 1.26-1.51$ ) and overall phases (nausea: $R R=1.54,95 \% \mathrm{Cl}: 1.31-1.81$; vomiting: $R R=1.31,95 \% \mathrm{Cl}: 1.18-1.46$ ). Furthermore, subgroup analysis based on THD dosage (100 vs $200 \mathrm{mg} /$ day) demonstrated no statistical significance with respect to overlapping $95 \% \mathrm{Cl}$. Thirty studies monitored the adverse events (AEs) of THD, all under grade 3 based on the CTCAE criteria. We compared the eight most common AEs; sedation, constipation, and drowsiness/dizziness were slightly frequent compared with controls.
\end{abstract}

Conclusion: THD is an effective adjuvant and a potential alternative in reducing delayed and overall CINV. Other regimens might be added for CINV during the acute phase.

Key words: Thalidomide, Chemotherapy-induced nausea and vomiting, Emesis

\section{Introduction}

Chemotherapy-induced nausea and vomiting (CINV) is caused by neurotransmitters and chemical substances stimulating the receptors in either the vomiting center or the chemoreceptor trigger zone. These substances include dopamine, serotonin, histamine, acetylcholine, and substance P (NK1) [1-4]. CINV needs to be well controlled because it often poses difficulties in chemotherapy, making it hard to maintain dose intensity and consequently reducing the patients' quality of life (QOL) [5]. The occurrence of CINV has been evaluated to be as high as $70-80 \%$ without proper antiemetic regimens [6]. Therapy has evolved considerably over the past four decades; the most recognizable and followed guidelines now recommend a four-drug combination including NK1 receptor antagonist, 5-HT3 receptor antagonist, 
dexamethasone, and olanzapine to prevent CINV in high emetic chemotherapy (HEC) [7, 8]. However, 60$80 \%$ of patients still experience CINV alongside chemotherapy [9], and the high cost of the present treatments for CINV also limit their clinical practice and promotion to an extent.

Thalidomide (THD) is a derivative of glutarnic acid, which was initially used as a sedative to treat emesis in pregnancy but was withdrawn from the market as it caused a serious adverse reaction to the fetal seal. THD could attenuate cisplatin-induced delayed emesis and decrease the levels of NK1 in the medulla and gastric tissues in a rat model [10]. In 2009, Liu et al. initially reported its significant effects in preventing chemotherapy-induced gastrointestinal side effects in the delayed phase following a modified FOLFOX7 regimen [11]. THD is also a powerful immunomodulatory and antiangiogenic drug that can inhibit the expression of vascular endothelial growth factor proteins and induce cell apoptosis [12]. The US food and drug Administration approved it as a treatment for multiple myeloma. Current studies have shown that chemotherapy combined with THD can be applied to treat solid carcinomas including lung cancer, breast cancer, gastric cancer, rectal cancer, and pancreatic cancer with a prominent curative effect [13-17]. A report also showed that THD could alleviate the symptoms accompanying malignant tumors, including cachexia, chronic nausea, insomnia, cancer pain, and dysesthesia [18].

Studies in succession have reported the notable effects of THD on CINV prevention during chemotherapy in patients with solid tumors in recent years. However, neither a systematic review nor a meta-analysis has been conducted based on the current progress. Therefore, we collected the studies related to THD in reducing nausea and emesis in chemotherapy patients and conducted an integrated analysis based on the currently available studies to see if it is an adjuvant for the currently recommended anti-CINV drugs or a potential alternative for antipsychotic or hormonal drugs for patients who cannot tolerate them.

\section{Methods}

\section{Search strategy}

A comprehensive literature search of all publication years up to Nov.30th 2019 was performed in PubMed, Embase, Cochrane, Web of science, CNKI, and Wanfang. The website of clinicaltrials.gov was searched for unpublished studies. Keywords related to intervention ("thalidomide" OR "sedoval" OR "thalomid" OR "N-phthaloylglutamic acid") were combined with keywords related to therapy ("chemotherapy*" NOT "radiotherapy*") and terms related to CINV ("chemotherapy-induced nausea and vomiting" OR "CINV" OR "nausea" OR "vomit" OR "emesis" OR "gastrointestinal side effect" OR "gastrointestinal dysfunction"). Furthermore, the reference lists of all searched studies were also taken into consideration.

\section{Study selection and criteria}

We evaluated the study eligibility with the PICO approach (population, intervention, comparison, and outcome). Only eligible randomized controlled trials (RCTs) contributed to the primary outcome assessment. Studies ineligible for the primary outcome but specifying the safety and QOL outcomes were included in analyzing the secondary outcomes.

Population: Patients received chemotherapy (e.g. cisplatin, oxaliplatin, nedaplatin). Any form of radiotherapy-involved treatment (e.g. Concurrent chemo-radiotherapy) was excluded.

Intervention: THD was used as an add-on treatment based on some regular anti-CINV regimen: 5-HT3 RA with or without dexamethasone/ methylprednisolone/metoclopramide.

Comparison: Eligible studies were required to apply the same regimen except for THD as the control group. Case studies, studies including two anti-CINV groups and no control group, and open trials without controlled pre-post designs were eliminated from the meta-analysis.

Outcome: Ranked data of nausea or vomiting degrees, or incidence rate of nausea or vomiting in the acute, delayed, or overall phase, which could be converted to the complete response rate were included. Studies providing effective response only, which equals the complete plus partial response, combining nausea and vomiting as a single outcome, were excluded.

\section{Quality assessment and data extraction}

Two investigators ( $\mathrm{N} \mathrm{W}$ and $\mathrm{P} \mathrm{X}$ ) independently reviewed the included studies and extracted relevant data with a prespecified table (Table 1). Extracted information included year of publication, first author, sample size, and subject characteristics (such as mean ages, cancer types, treatment, and comparability of QOL). The overall quality of included studies analyzing the primary outcome was assessed according to the criteria for bias risk assessment in the Cochrane collaboration handbook 5.1.4[19]. All eligible trials reported the application of randomization. Among these, two studies mentioned the method of randomization [20, 21]: one used a computer-generated sequence [20], another used a random number table [21]; the remaining studies did 
not report any details of randomization. None of the studies reported whether the treatment allocation was concealed except for one that used identical capsules [20]. Five studies [22-26] used a double-blinding method and one [20] used a triple-blinding method in the experimental process. Studies presenting the data with endpoints of subjects and baseline characteristics were regarded as reporting complete data. We further differentiated "other sources of bias" with three subdomains: "enrolment" (e.g. ratio of total attended to planned participants), adherence (e.g. ratio of planned therapy cycles successfully finished with the planned dosage in cycles attended), and loss to follow-up (e.g. uneven dropouts between the intervention and control groups). The detailed information about quality evaluation in each study is presented in Figure 2.

\section{Outcomes of interest}

The primary endpoint was the rate of complete response (CR) for nausea and vomiting in the acute, delayed, and overall phases. The secondary endpoint was the safety of THD, which was assessed based on the common terminology criteria for adverse events (CTCAE) and patients' QOL changes, assessed by Karnofsky Performance Status (KPS) scores.

\section{Statistical analysis}

For the primary endpoint, studies were stratified by the reaction phases (acute, delayed, overall) of prognosis (nausea and emesis). Pooled risk ratios (RRs) with $95 \% \mathrm{CI}$ weighted by the Mantel-Haenszel method in the fixed model were used to calculate the difference of CR between the THD and control groups. The difference was tested with $\alpha=0.01$. Subgroup analysis was performed based on the THD dosage (100 vs $200 \mathrm{mg} /$ day) to investigate different therapeutic effects. The patients' QOL was estimated by improved rates of KPS scores, and the safety of THD was calculated by the pooled odds ratio (OR) in the fixed model.

Heterogeneity was investigated by $\mathrm{I}^{2}$ and $\mathrm{Q}$ statistics [27]. A more liberal $P$ value of $\leq 0.10$ was referred to signify heterogeneity, considering the generally low statistical power of heterogeneity tests [28]. The $\mathrm{I}^{2}$ statistic is an estimate of variance in a pooled effect size, which is explained by heterogeneity in the study samples and is unaffected by the study quantities (K) [29]. Values of $0 \%, 25 \%$, $50 \%$, and $75 \%$ were determined to indicate no, low, moderate, and high heterogeneity, respectively.

Negative and positive findings are partially published to some extent, and publication bias is a widespread problem when reviewing the available references [30]. We assessed publication bias using funnel plots and Egger's test [31-33]. If the results suggested possible publication bias, adjusted ESs were computed with the Duval and Tweedie trim-and-fill method [34]. We calculated a failsafe number in case of statistically significant results [33, 35]. This failsafe number is the number of unpublished studies without findings, which would reduce the results to statistical non-significance $(P>$ 0.05). We also tested the robustness of the results by comparing the suggested criterion $(5 K+10)$ to the failsafe number [35].

\section{Results}

\section{Characteristics of included studies}

In total, 283 studies were identified by screening the six databases mentioned above. We excluded 149 duplicates and reviewed the abstracts of the remaining 134 studies based on our inclusion and exclusion criteria. 47 studies met the eligibility criteria and were inspected further. We found that 13 of them were from duplicate population. Another 20 studies were combined in the secondary outcome analysis. Among these, 16 studies were excluded from the primary outcome analysis as they combined nausea and emesis as a single outcome or offered indefinite data (e.g. unable to extract complete response measurement). 4 studies were eliminated for comparison with positive control (e.g. dexamethasone/metoclopramide). Finally, 14 RCTs were subjected to our first endpoint meta-analysis. The flowchart of the study selection is shown in Figure 1.

The characteristics of the included studies are detailed in Table 1. The number of patients in the 14 RCTs varied from 52 to 638. Overall, 877 (50\%, mean standard deviation age: $55 \pm 5.5$ years) and $867(50 \%$, mean standard deviation age: $56 \pm 4.4$ years) patients allocated to THD and control groups, respectively, were evaluated. The CR data of nausea and vomiting in the three phases were extracted from two studies $[20,22]$, with one presenting the original data on five separate days and over the entire study duration [22]. We selected the smallest records from days 2-5 of the two groups as the relative conservative indicator for the patient number that achieved CR in the delayed phase. One study offered the rates of CR for nausea in the three phases [23]. The CR data for nausea and vomiting in the acute and delayed phases were extracted from four studies [21,36-38] with one giving the original data on five separate days [38]. Smallest records from days 2-5 of the two groups were extracted respectively to indicate the patient number that achieved CR in the delayed phase. One study reported the rates of $C R$ for nausea and vomiting in 
the acute phase [11]. Three studies reported the rates of CR of nausea and vomiting in the overall phase [26, $39,40]$. Two studies reported the rate of CR for vomiting in the overall phase [24,41], and one in the delayed phase [25]. Four of the included studies $[24-26,40]$ were from two same authors but were four independent trials with different patient characteristics, anti-CINV regimens, and cared outcome phases. Most studies used platinum drug-based combined chemotherapy, such as cisplatin, oxaliplatin, and nedaplatin of which cisplatin was most used.

\section{Primary endpoint (no nausea and no vomiting)}

In the selected 14 RCTs, the CR for nausea in the THD group did not significantly differ from that in the control during the acute phase $(\mathrm{RR}=1.11,95 \% \mathrm{CI}$ : 1.02-1.21, $P>0.01$; Figure 3A). The positive result of $\mathrm{RR}$ with the lower limit of $95 \% \mathrm{CI}$ extremely close to 1 may be attributed to sampling error, since none of the studies in the acute phase showed a positive result. However, patients in the THD group showed a statistically better CR during both the delayed (RR = 1.69, 95\% CI: 1.47-1.94, $P<0.01$ Figure 3A) and overall phase $(\mathrm{RR}=1.54,95 \% \mathrm{CI}: 1.31-1.81, P<0.01$ Figure 3A) compared to the control group.

The CR for chemotherapy-induced vomiting in the THD group did not significantly differ from that in the control during the acute phase $(R R=1.08$ 95\%CI: $1.02-1.16, \quad P>0.01$ Figure 3B). We did not impart much clinical meaning to the pooled RR as well as the result of acute nausea. However, patients in the THD group had a statistically positive CR during both the delayed $(\mathrm{RR}=1.38,95 \% \mathrm{CI}$ : 1.26-1.51, $P<0.01$ Figure 3B) and overall phase $(\mathrm{RR}=1.31$, 95\% CI 1.18-1.46, $P<0.01$, Figure 3B) compared with the control.

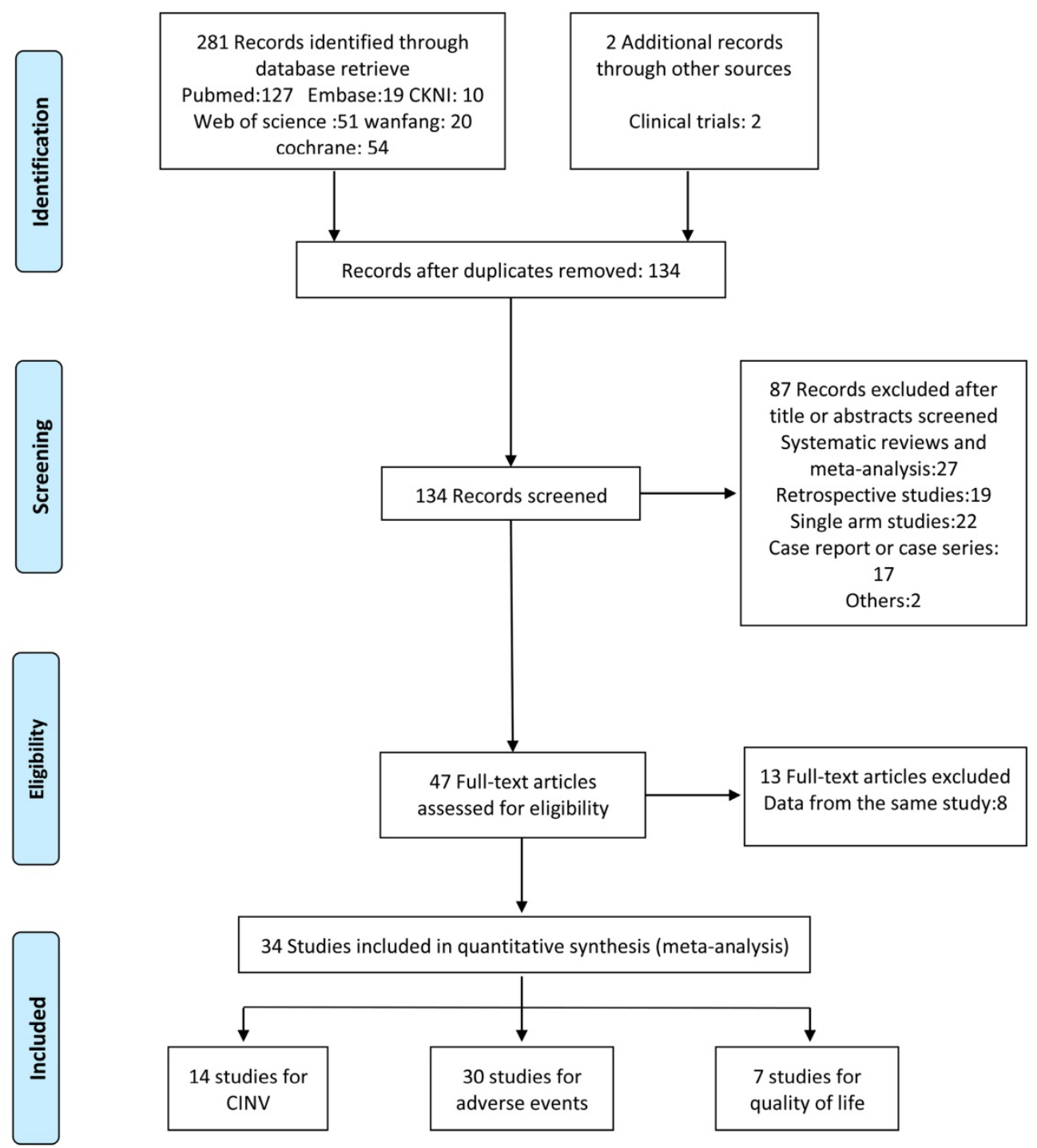

Figure 1. Study selection flowchart. 
Table 1. Baseline characteristics of 34 studies for meta-analysis

\begin{tabular}{|c|c|c|c|c|c|c|c|c|c|c|c|c|c|}
\hline \multirow[t]{2}{*}{ First author } & \multirow{2}{*}{$\begin{array}{l}\text { Study } \\
\text { design }\end{array}$} & \multicolumn{2}{|c|}{ Number } & \multicolumn{2}{|c|}{ Sexes } & \multicolumn{2}{|l|}{ Age } & \multirow{2}{*}{$\begin{array}{l}\text { Cancer } \\
\text { Types }\end{array}$} & \multirow{2}{*}{$\begin{array}{l}\text { Therapeutic } \\
\text { Regimen }\end{array}$} & \multirow{2}{*}{$\begin{array}{l}\text { Antiemetic } \\
\text { Regimen }\end{array}$} & \multirow{2}{*}{$\begin{array}{l}\text { QOL before } \\
\text { treatment }\end{array}$} & \multirow{2}{*}{$\begin{array}{l}\text { Dosage } \\
(\mathrm{mg} / \mathrm{d})\end{array}$} & \multirow{2}{*}{ Outcomes } \\
\hline & & $\mathrm{T}+\mathrm{C}$ & $\mathrm{C}$ & Male & Female & $\mathrm{T}+\mathrm{C}$ & C & & & & & & \\
\hline Cui Y 2011 & RCS & 26 & 26 & 0 & 56 & NR & & $\mathrm{B}$ & AC-T & Tro+THD VS Tro+DEX & $\begin{array}{l}\text { ECOG PS } \\
0-2\end{array}$ & $25 \mathrm{X} 2$ & AEs \\
\hline Chen YL 2012 & $\mathrm{RCT}$ & 25 & 28 & 31 & 22 & 58.1 & 57.9 & $\mathrm{~L}+\mathrm{C}+\mathrm{B}$ & Cisplatin-based & Tro+THD & $\mathrm{KPS} \geq 70$ & $50 \times 3$ & $\begin{array}{l}\text { Anti-nausea and } \\
\text { vomiting }(\mathrm{O})\end{array}$ \\
\hline Cao YX 2016 & $\mathrm{RCT}$ & 30 & 30 & 31 & 29 & 45.98 & 50.53 & $\mathrm{~L}+\mathrm{C}+\mathrm{B}$ & Cisplatin-based & PAL+THD VS PAL & $\begin{array}{l}\text { ECOG PS } \\
0-2\end{array}$ & $100 \times 1$ & $\begin{array}{l}\text { Anti-nausea and } \\
\text { vomiting }(\mathrm{O})\end{array}$ \\
\hline Cao $Y X^{*} 2016$ & RCT & 30 & 30 & 35 & 25 & 68.25 & 64.6 & $\mathrm{~L}+\mathrm{G}+\mathrm{C}$ & NR & PAL+THD VS PAL & NR & $100 \times 1$ & $\begin{array}{l}\text { Anti-nausea and } \\
\text { vomiting }(\mathrm{O})\end{array}$ \\
\hline $\begin{array}{l}\text { Cheng QL } \\
2018\end{array}$ & RCS & 45 & 45 & 0 & 90 & 54.91 & 55.09 & $C^{*}$ & Cisplatin-contained & PAL+THD VS PAL & NR & $50 \times 1$ & AEs \\
\hline Feng G 2015 & RCT & 35 & 35 & 25 & 20 & 58 & 57 & $\mathrm{~L}+\mathrm{E}+\mathrm{O}$ & NDP-contained & Aza+THD VS Aza & $\begin{array}{l}\text { KPS } \\
9596\end{array}$ & $200 \times 1$ & AEs \\
\hline Gu AQ 2009 & RCS & 33 & 33 & 20 & 21 & 56 & 54 & NSCLC & $\mathrm{NP}$ & THD VS placebo & $\begin{array}{l}\text { ECOG PS } \\
0-2\end{array}$ & $200 \times 1$ & AEs \\
\hline He QS 2008 & RCT & 21 & 20 & 20 & 21 & 56 & 54 & NSCLC & NP & THD VS placebo & $\begin{array}{l}\text { ECOG PS } \\
0-2\end{array}$ & 200 & AEs \\
\hline Han ZX 2014 & $\mathrm{RCT}$ & 38 & 32 & 40 & 30 & 50 & & $\mathrm{~L}+\mathrm{G}+\mathrm{O}$ & Cisplatin-contained & Tro+THD VS Tro & KPS $>60$ & $100-200$ & Anti-vomiting(O);QOL \\
\hline Han ZX 2016 & $\mathrm{RCT}$ & 40 & 38 & 45 & 33 & 50.4 & 50.2 & $\mathrm{~L}+\mathrm{G}+\mathrm{O}$ & Cisplatin-contained & Aza+TDH VS Aza & $\mathrm{KPS} \geq 60$ & $100-200$ & Anti-vomiting(D);AEs;QOL \\
\hline $\begin{array}{l}\text { Jiang WM } \\
2010\end{array}$ & CCS & 31 & 30 & 40 & 21 & 56 & 57 & NSCLC & GP & THD VS placebo & $\begin{array}{l}\text { ECOG PS } \\
0-2\end{array}$ & $200 \times 1$ & AEs \\
\hline Jiang HR 2017 & $\mathrm{RCT}$ & 138 & 128 & 94 & 172 & 59.4 & 59.5 & $\mathrm{~L}+\mathrm{B}$ & $\begin{array}{l}\text { CE or } \\
\text { cisplatin-contained }\end{array}$ & $\begin{array}{l}\text { PAL+DEX+THD } \\
\text { VS PAL+DEX }\end{array}$ & $\begin{array}{l}\text { ECOG PS } \\
0-2\end{array}$ & $100 \times 2$ & Anti-nausea(A;D;O);AEs \\
\hline Luo Q 2011 & RCS & 26 & 28 & 42 & 12 & 60 & 59 & NSCLC & GP & THD VS placebo & $\mathrm{KPS} \geq 70$ & $100-200$ & QOL \\
\hline Liu YP 2009 & $\mathrm{RCT}$ & 26 & 26 & 35 & 17 & 55.5 & 54 & $\mathrm{G}+\mathrm{C}+\mathrm{O}^{*}$ & mFOLFOX7 & $\begin{array}{l}\text { RAM+DEX+THD VS } \\
\text { RAM+DEX }\end{array}$ & $\begin{array}{l}\text { ECOG PS } \\
0-2\end{array}$ & $150 \times 2$ & $\begin{array}{l}\text { Anti-nausea and } \\
\text { vomiting(A); AEs }\end{array}$ \\
\hline Li M 2016 & $\mathrm{RCT}$ & 30 & 30 & 35 & 25 & 56.8 & 57.7 & $\mathrm{~L}$ & Cisplatin-contained & $\begin{array}{l}\text { OND+DEX+THD VS } \\
\text { OND+DEX }\end{array}$ & $\begin{array}{l}\text { ECOG PS } \\
0-2\end{array}$ & $100 \times 1$ & $\begin{array}{l}\text { Anti-nausea and } \\
\text { vomiting(A;D);AEs }\end{array}$ \\
\hline Peng Y 2014 & RCT & 31 & 31 & 38 & 24 & 68.5 & 69.7 & NSCLC & $\mathrm{TP}$ & $\begin{array}{l}\text { 5-HT3 RA+THD VS } \\
\text { 5-HT3RA }\end{array}$ & $\mathrm{KPS} \geq 60$ & $100-200$ & AEs; QOL \\
\hline Qv H 2018 & CCS & 47 & 47 & 0 & 94 & 46.81 & 47.52 & $\mathrm{O}$ & TC & Tro+THD VS Tro & $\mathrm{KPS} \geq 70$ & $50 \times 1$ & AEs \\
\hline Shen ZL 2009 & CCS & 26 & 10 & 22 & 14 & 46.8 & 45.2 & NSCLC & $\mathrm{NP}$ & THD VS placebo & $\begin{array}{l}\text { ECOG PS } \\
0-2\end{array}$ & $100-400$ & AEs \\
\hline Song XQ 2010 & RCS & 35 & 31 & 52 & 14 & 56 & 55 & NSCLC & Cisplatin-based & THD VS placebo & $\begin{array}{l}\text { ECOG PS } \\
0-2\end{array}$ & $300 \times 1$ & AEs \\
\hline She MJ 2010 & $\mathrm{RCT}$ & 33 & 32 & 44 & 21 & NR & & E & $\mathrm{FP}$ & $\begin{array}{l}\text { OND+Met+THD VS } \\
\text { OND+Met }\end{array}$ & $\mathrm{KPS} \geq 70$ & $100-200$ & AEs; QOL \\
\hline Sun YL 2010 & CCS & 36 & 21 & 31 & 26 & 54 & 52 & NSCLC & $\mathrm{NP}$ & THD VS placebo & $\begin{array}{l}\text { ECOG PS } \\
0-2\end{array}$ & $200 \times 1$ & AEs \\
\hline Song XG 2010 & RCS & 35 & 31 & 52 & 14 & 56 & 55 & NSCLC & Cisplatin-based & THD VS placebo & $\begin{array}{l}\text { ECOG PS } \\
0-2\end{array}$ & $300 \times 1$ & AEs \\
\hline Sun XQ 2011 & CCS & 30 & 30 & 36 & 24 & 57.5 & & NSCLC & DP & THD VS placebo & $\begin{array}{l}\text { ECOG PS } \\
0-2\end{array}$ & $300 \times 1$ & AEs \\
\hline Song G 2017 & $\mathrm{RCT}$ & 40 & 43 & 57 & 26 & 57 & 54 & $\mathrm{G}+\mathrm{L}+\mathrm{E}$ & FP or EP & $\begin{array}{l}\text { OND+MET+DEX+THD } \\
\text { VS OND+MET+DEX }\end{array}$ & KPS 70-100 & $100 \times 1$ & $\begin{array}{l}\text { Anti-nausea and } \\
\text { vomiting }(\mathrm{A} ; \mathrm{D} ; \mathrm{O}) ; \mathrm{AEs}\end{array}$ \\
\hline Wang SS 2018 & RCT & 40 & 40 & 55 & 25 & 52.21 & 51.47 & $\mathrm{~L}$ & Cisplatin-contained & $\begin{array}{l}\text { PAL+DEX+THD } \\
\text { VS PAL+DEX }\end{array}$ & $\begin{array}{l}\text { ECOG PS } \\
0-1\end{array}$ & $100 \times 1$ & Anti-vomiting $(\mathrm{O})$ \\
\hline Xu SN 2010 & CCS & 30 & 30 & 32 & 28 & 55 & & $\mathrm{E}$ & $\mathrm{PTX}+\mathrm{NDP}$ & THD VS Placebo & $\begin{array}{l}\text { ECOG PS } \\
0-1\end{array}$ & $100-300$ & AEs \\
\hline Yu YL 2009 & $\mathrm{RCT}$ & 30 & 31 & 29 & 32 & 58 & 62 & NSCLC & GP & $\begin{array}{l}\text { Ram+Met+THD VS } \\
\text { Ram+Met }\end{array}$ & $\begin{array}{l}\text { ECOG PS } \\
11\end{array}$ & $50 \times 2$ & $\begin{array}{l}\text { Anti-nausea and } \\
\text { vomiting }(A ; D)\end{array}$ \\
\hline $\begin{array}{l}\text { Zhang GJ } \\
2008\end{array}$ & $\mathrm{RCT}$ & 30 & 30 & 39 & 21 & 57 & & NSCLC & DP & THD VS placebo & $\begin{array}{l}\text { ECOG PS } \\
0-2\end{array}$ & 300 & AEs \\
\hline Zhu ZT 2010 & RCS & $\begin{array}{l}40 \\
40\end{array}$ & & 50 & 30 & 48 & & NSCLC & GP & $\begin{array}{l}\text { RAM+DEX+THD VS } \\
\text { RAM+DEX+Met }\end{array}$ & NR & $50 \times 2$ & AEs \\
\hline Zuo CY 2014 & $\mathrm{RCT}$ & 41 & 40 & 0 & 82 & 55 & 57 & $\mathrm{MBC}$ & GP & Tro+THD VS Tro & KPS $60-90$ & $25 \times 2$ & $\begin{array}{l}\text { Anti-nausea and } \\
\text { vomiting(A;D);AEs }\end{array}$ \\
\hline Zhang J 2016 & RCT & 52 & 50 & 58 & 44 & NR & & SCLC & EP or IP & $\begin{array}{l}\text { PAL+MP+THD VS } \\
\text { Tro+MP }\end{array}$ & $\mathrm{KPS} \geq 70$ & $100 \times 1$ & $\begin{array}{l}\text { Anti-nausea and } \\
\text { vomiting }(\mathrm{A} ; \mathrm{D}) ; \mathrm{AEs} ; \mathrm{QOL}\end{array}$ \\
\hline Zhao W 2016 & RCS & 39 & 39 & 42 & 36 & 57.2 & & NR & Cisplatin-contained & $\begin{array}{l}\text { Tro+DEX+THD VS } \\
\text { Tro+DEX }\end{array}$ & NR & $25 \times 2$ & AEs \\
\hline Zhao Y 2017 & RCS & 33 & 33 & 36 & 30 & 57.5 & & $\mathrm{~L}$ & GP & THD VS Tro & $\begin{array}{l}\text { ECOG PS } \\
0-2\end{array}$ & $100 \times 1$ & QOL \\
\hline $\begin{array}{l}\text { Zhang LY } \\
2017\end{array}$ & $\mathrm{RCT}$ & 317 & 321 & 195 & 443 & 53 & 54 & $\mathrm{~L}+\mathrm{B}+\mathrm{O}^{*}$ & $\begin{array}{l}\text { CE or } \\
\text { cisplatin-contained }\end{array}$ & $\begin{array}{l}\text { PAL+DEX+THD VS } \\
\text { PAL+DEX }\end{array}$ & $\begin{array}{l}\text { ECOG PS } \\
0-2\end{array}$ & $100 \times 2$ & $\begin{array}{l}\text { Anti-nausea and } \\
\text { vomiting }(\mathrm{A} ; \mathrm{D} ; \mathrm{O}) ; \mathrm{AEs}\end{array}$ \\
\hline
\end{tabular}

Abbreviations:

RCT: Randomized Clinical Trials; RCS: Retrospective Cohort Studies; CCS: Case Control Studies; T+C: Thalidomide group; C: Control group; L: Lung cancer; B: Breast cancer; G: Gastric cancer; C: Colorectal cancer; C*: Cervical cancer; O: Ovarian cancer; O*: Others; E: Esophageal cancer; NSCLC: Non-small cell lung cancer; SCLC: Small cell lung cancer; MBC: metastatic breast cancer; CE: Carboplatin+VP16; mFOLFOX7: Oxaliplatin+ Calcium Folinatc+ Fluorouracil; EP: VP16+ Cisplatin; GP: Gemcitabine+ Cisplatin; IP: Irinotecan+ Cisplatin; TC: Paclitaxel+ Carboplatin; AC-T: Anthracycline+ Cytotoxic agent-Taxol drugs; PTX: Paclitaxel; NDP: Nedaplatin; TP: Paclitaxel+ Cisplatin; FP: Fluorouracil+ Cisplatin; DP: Docetaxel+ Cisplatin; NP: Vinorelbine+ Cisplatin; Tro: Tropisetron; Aza: Azasetron; RAM: Ramosetron; DEX: Dexamethasone; PAL: Palonosetron; Met: Metoclopramide; MP: Methylprednisolone OND: Ondansetron; THD: Thalidomide; QOL: Quality of life; KPS: Karnofsky Performance Status; ECOG: The Eastern Cooperative Oncology Group; A: Acute phase; D: Delayed phase; O: Overall phase; AEs: Adverse Effects; NR: Not Reported 


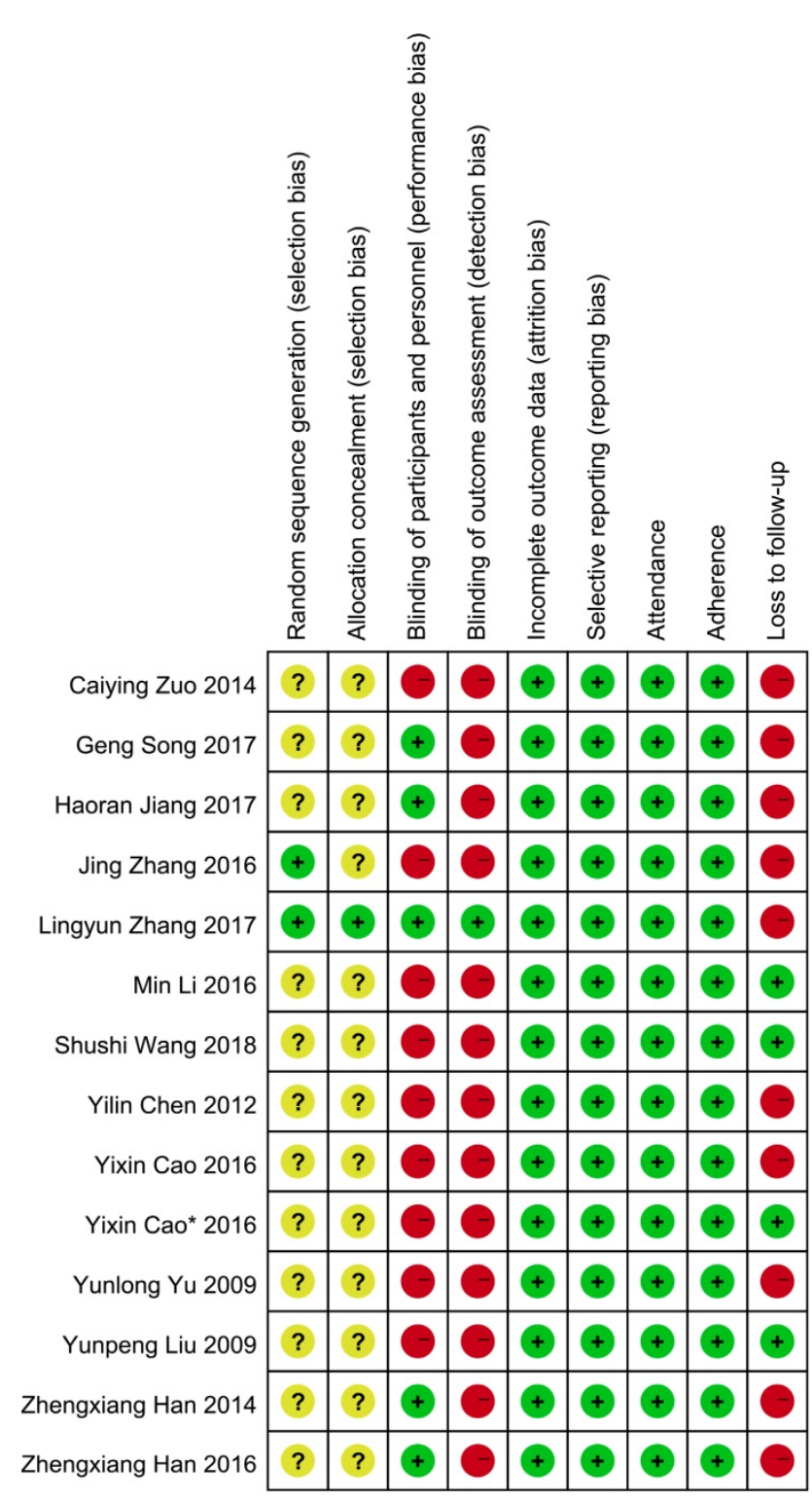

Figure 2. Risk of bias. Notes: Green cycle with plus sign indicates a low risk of bias; Yellow cycle with question mark indicates an unclear risk of bias; Red cycle with minus sign indicates a high risk of bias.

Subgroup analysis based on the THD dosage was conducted. We extracted all data on delayed vomiting (for its rather high heterogeneity), overall vomiting data (studies [24, 26, 40,41] only provided the overall vomiting data were used as an indicator of the delayed phase ones), and one case of delayed nausea (vomiting was not an outcome in that study [23]). Outcomes from acute phase were not considered in view of the limited effect, which might compromise the statistical power. Emetic chemotherapies of the 10 studies were all cisplatin-contained regimens, which was HEC. In those studies, THD was used in the range of 50-200 $\mathrm{mg} /$ day, and 100 and $200 \mathrm{mg}$ / day were mostly used. The $95 \% \mathrm{CI}$ of pooled RR was compared between the effect of $100 \mathrm{mg} /$ day $(\mathrm{RR}=1.59,95 \% \mathrm{CI} 1.36-1.87, P<$
0.01; Figure 4) and $200 \mathrm{mg} /$ day $(\mathrm{RR}=1.35,95 \% \mathrm{CI}$ 1.22-1.50, $P<0.01$; Figure 4) of THD. The overlapping of $95 \% \mathrm{CI}$ meant no statistical difference.

\section{Publication bias}

The results for nausea in the three phases and vomiting in the acute and overall phase were regarded as statistically homogeneous $\left(\mathrm{I}^{2}<50 \% P>\right.$ $0.1)$. Statistical heterogeneity $\left(\mathrm{I}^{2}=58.6 \% \quad P=0.02\right)$ within the delayed vomiting group was shown by the Egger's test, which was used to evaluate the publication bias ( $P=0.01,95 \% \mathrm{CI}$ : 1.05-5.23). The adjusted summary estimate was calculated using the Duval and Tweedie trim-and-fill method, the SE hardly changed after three supplementary studies as shown in Figure 5. Therefore, publication bias did not affect the stability of the outcome. The Rosenthal failsafe number 104 was also calculated and outdistanced the suggested criterion: $45(5 \mathrm{~K}+10)$, which testified a robust result.

\section{Safety of thalidomide}

No grade 3 or 4 side effects were reported in the THD group in the 39 studies according to the CTCAE criteria. Sedation was the most common adverse event reported followed by constipation and drowsiness/dizziness. It seemed that THD was relatively safe except that the rate of peripheral neuropathy $(P=0.06)$ differed significantly between the THD and control groups as shown in Table 2.

\section{Quality of life (QOL)}

The evaluation indexes of patients' QOL were insufficient and non-standard. We pooled six improved rates of KPS scores [14, 21, 24, 25, 42, 43], which were the mostly used standards in our related studies and one ECOG score [44] converted to that. The result was significant ( $R R=2.4195 \% \mathrm{CI}$ : 1.63-3.56; $P<0.01$, Figure 6). Criteria like SAS \& SDS [26], QOL questionnaire C30 by European Organization for Research and Treatment of Cancer [20] and CAT [18] also showed statistically better results of the patients' appetite, sleep quality and emotion in the THD group as well as patients' sensation of wellbeing [45].

\section{Discussion}

This meta-analysis investigated the add-on prophylactic treatment potential of THD for CINV. Complete response rates of nausea and vomiting were significantly higher in the THD-treated group in the delayed and overall phases than the acute phase. As for studies were not included in our analysis for comparison with non-blank group (e.g. metoclopramide/dexamethasone) [44, 46-48], the THD group also showed a statistically better control of nausea and 
emesis in the delayed phase. In most of our included studies, THD was administered at 50-200 mg/day, with $100 \mathrm{mg} /$ day being the most common. Subgroup analysis based on the dosage suggested no statistical significance between the $200 \mathrm{mg} /$ day dose compared with the $100 \mathrm{mg} /$ day dose. We thus suggest the dose of $100 \mathrm{mg}$ /day of THD for prophylaxis of CINV in consideration of adverse events (AEs). Nevertheless, this recommendation is speculative, given an incomprehensive dose gradient and the small number of pooled trials.

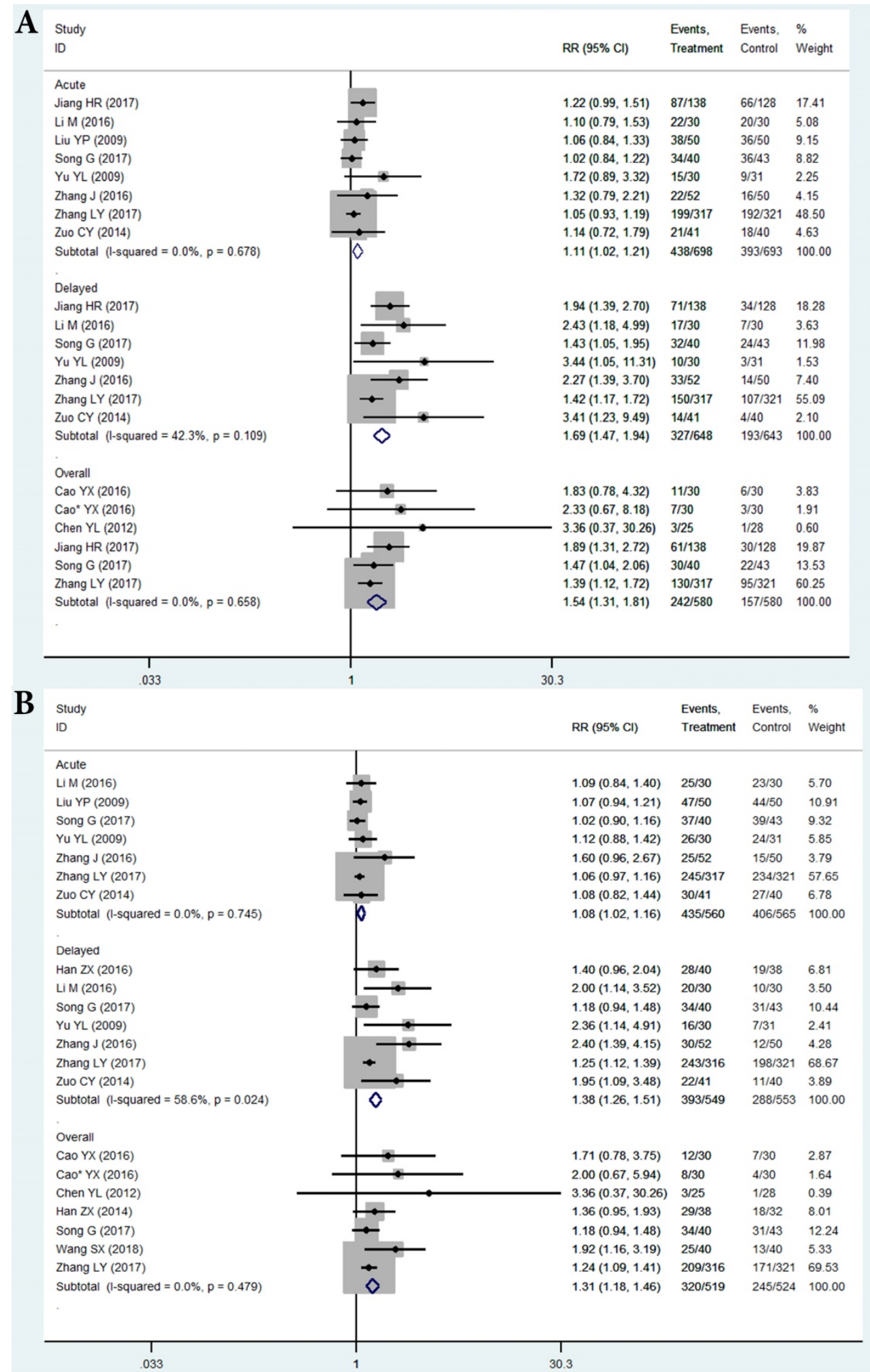

Figure 3. A. Forest plot of effect sizes for effects of thalidomide on anti-chemotherapy induced nausea in the three phases (acute, delayed and overall). B. Forest plot of effect sizes for effects of thalidomide on anti-chemotherapy induced vomiting in the three phases (acute, delayed and overall). 
Study

ID
Events, Events, \%

$\mathrm{RR}(95 \% \mathrm{Cl}) \quad$ Treatment Control Weight
$100 \mathrm{mg} / \mathrm{mL}$

Cao YX (2016)

Cao* YX (2016)

Han ZX (2016)

Han ZX (2014)

Li M (2016)

Song G (2017)

Wang SS (2018)

Zhang J (2016)

Subtotal $(\mathrm{I}$-squared $=39.3 \%, p=0.117$ )

$200 \mathrm{mg} / \mathrm{mL}$

Jiang HR (2017)

Zhang LY (2017)

Subtotal $(\mathrm{I}$-squared $=85.3 \%, p=0.009$ )

.

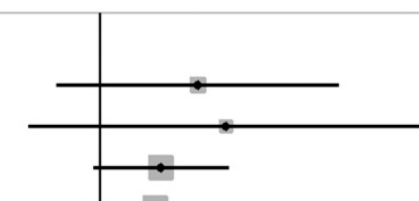

$1.71(0.78,3.75) 12 / 30 \quad 7 / 30 \quad 6.08$

$2.00(0.67,5.94) 8 / 30 \quad 4 / 30 \quad 3.47$

$1.40(0.96,2.04) 28 / 40 \quad 19 / 38 \quad 16.92$

$1.36(0.95,1.93) 29 / 38 \quad 18 / 32 \quad 16.97$

$2.00(1.14,3.52) 20 / 30 \quad 10 / 30 \quad 8.68$

$1.18(0.94,1.48) 34 / 40 \quad 31 / 43 \quad 25.95$

$1.92(1.16,3.19) 25 / 40 \quad 13 / 40 \quad 11.29$

$2.40(1.39,4.15) 30 / 52 \quad 12 / 50 \quad 10.63$

$1.59(1.36,1.87) 186 / 300 \quad 114 / 293 \quad 100.00$

$1.94(1.39,2.70) 71 / 138 \quad 34 / 128 \quad 15.22$

$1.25(1.12,1.39) 243 / 316 \quad 198 / 32184.78$

$1.35(1.22,1.50) 314 / 454 \quad 232 / 449 \quad 100.00$

\begin{tabular}{ccc}
\multicolumn{2}{c}{} & \multicolumn{2}{|c}{} \\
\hline .168 & 1 & 5.94
\end{tabular}

Figure 4. Forest plot of effect sizes for effects of subgrouped thalidomide dosages (100 vs $200 \mathrm{mg} / \mathrm{d}$ ) on CINV in the delayed phase.

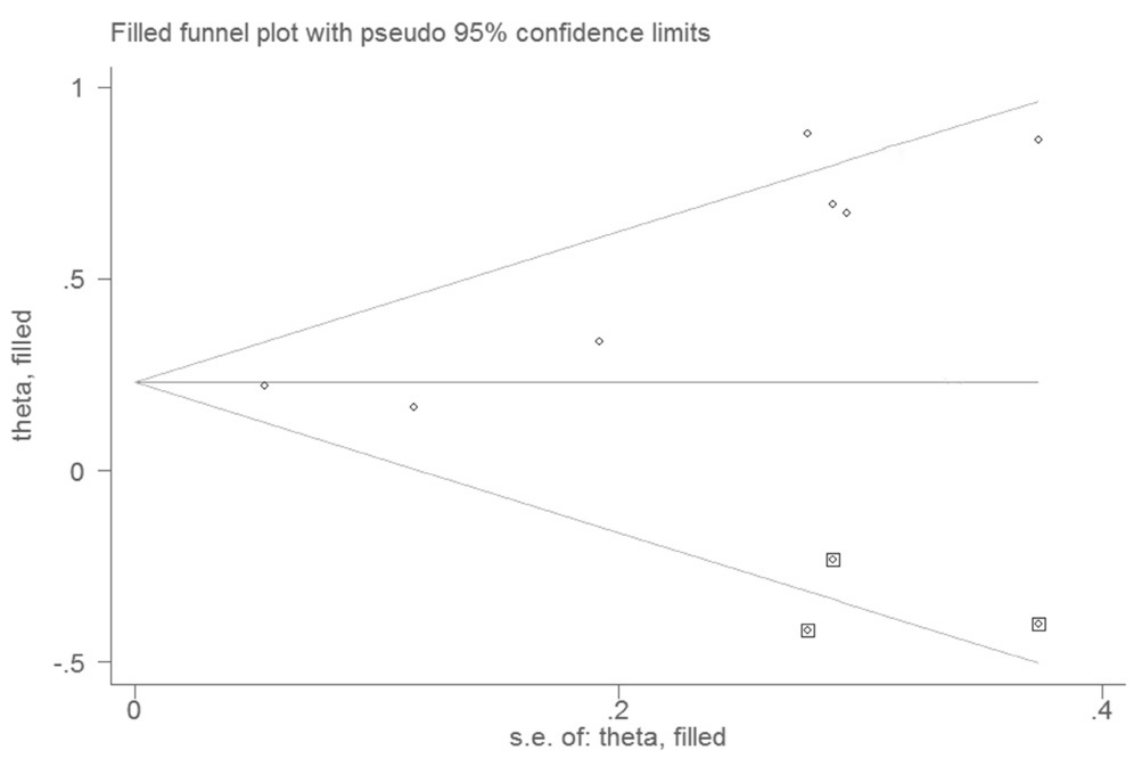

Original

Meta-analysis

\begin{tabular}{lcccccc}
\multicolumn{1}{c}{ I } & Pooled & \multicolumn{2}{c}{$95 \%$ Cl } & \multicolumn{2}{c}{ Asymptotic } & No. of \\
Method I & Est & Lower & Upper & z_value & p_value & studies \\
\hline Fixed I & 1.380 & 1.258 & 1.515 & 6.80 & 0.000 & 7 \\
Random I & 1.513 & 1.231 & 1.860 & 3.93 & 0.000 &
\end{tabular}

Filled

Meta-analysis (exponential form)

\begin{tabular}{lcccccc} 
& \multicolumn{2}{c}{ I } & Pooled & \multicolumn{2}{c}{$95 \%$ Cl } & \multicolumn{2}{c}{ Asymptotic } & No. of \\
Method I & Est & Lower & Upper & z_value & p_value & studies \\
\hline Fixed I & 1.258 & 1.155 & 1.370 & 5.251 & 0.000 & 10 \\
Random I & 1.303 & 1.059 & 1.603 & 2.502 & 0.012 &
\end{tabular}

Figure 5. Publication bias after Duval and Tweedie trim-and-fill method. Abbreviations: Est: estimates 
Table 2. Adverse events comparison between thalidomide and control group

\begin{tabular}{|c|c|c|c|c|c|c|c|c|c|c|}
\hline \multirow[t]{2}{*}{ Adverse Effects } & \multirow[t]{2}{*}{ Included studies } & \multicolumn{2}{|c|}{$\mathrm{T}+\mathrm{C}$} & \multicolumn{2}{|l|}{ C } & \multicolumn{2}{|c|}{ Heterogeneity analysis } & \multirow[t]{2}{*}{ Statistical analysis model } & \multicolumn{2}{|c|}{ Statistical analysis } \\
\hline & & $\mathrm{n}$ & $\mathbf{N}$ & $\mathbf{n}$ & $\mathbf{N}$ & $\mathbf{I}^{2}$ & p & & OR(95\%CI) & $\mathbf{P}$ \\
\hline Myelosuppression & 8 & 110 & 297 & 115 & 304 & $0.00 \%$ & 0.94 & Fixed effect model & $0.98(0.69-1.39)$ & 0.89 \\
\hline Constipation & 27 & 547 & 1288 & 366 & 1246 & $36.20 \%$ & 0.06 & Fixed effect model & $1.84(1.54-2.19)$ & $<0.01$ \\
\hline Drowsiness/Dizziness & 21 & 324 & 938 & 151 & 861 & $66.80 \%$ & $<0.01$ & Fixed effect model & $2.67(2.14-3.34)$ & $<0.01$ \\
\hline Sedation & 4 & 81 & 437 & 29 & 443 & $21.20 \%$ & 0.28 & Fixed effect model & $3.37(2.15-5.31)$ & $<0.01$ \\
\hline Rash & 14 & 76 & 595 & 55 & 527 & $55.60 \%$ & 0.02 & Fixed effect model & $1.31(0.91-1.89)$ & 0.15 \\
\hline Diarrhea & 6 & 60 & 606 & 41 & 589 & $0.00 \%$ & 0.85 & Fixed effect model & $1.44(0.94-2.19)$ & 0.09 \\
\hline Peripheral neuropathy & 14 & 85 & 531 & 55 & 504 & $0.00 \%$ & 0.58 & Fixed effect model & $1.58(1.14-2.18)$ & 0.06 \\
\hline Hepatorenal damage & 10 & 64 & 358 & 59 & 354 & $0.00 \%$ & 0.97 & Fixed effect model & $1.07(0.72-1.58)$ & 0.74 \\
\hline
\end{tabular}

Abbreviations:

$\mathrm{T}+\mathrm{C}$ : Thalidomide group; $\mathrm{C}$ : Control group; $\mathrm{n}$ : number of patients have adverse events; N: number of patients allocated to the two groups

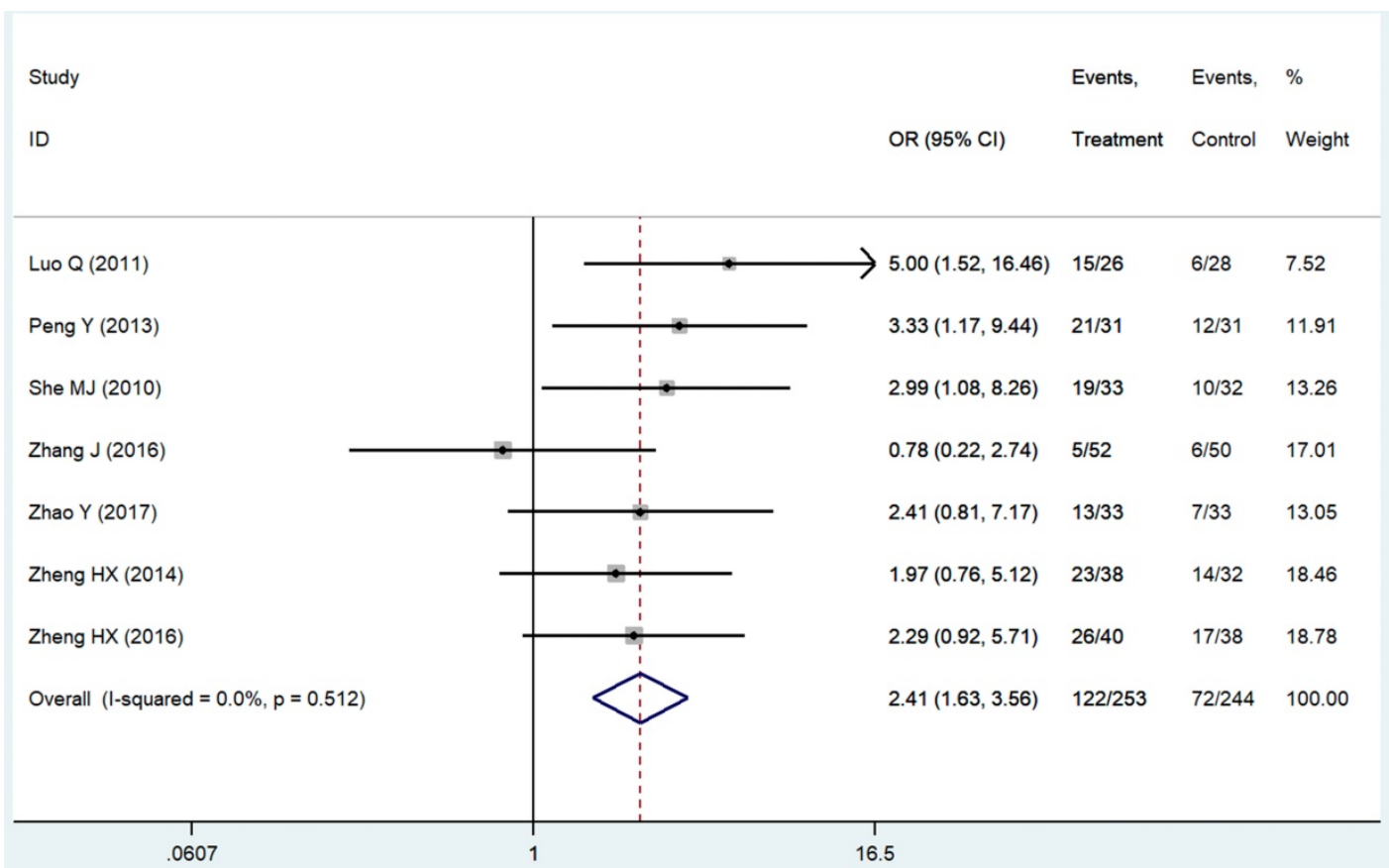

Figure 6. Forest plot of effect sizes for effects of thalidomide on patients' quality of life.

Essentially, risks related to THD today remain the same as those when it was originally produced and marketed in more than 45 countries, nearly 70 years ago. The overall side effects of THD are well understood as different patient populations have been exposed for decades of clinical application. However, chemotherapy patients do not bear the risk of birth defects. Other common AEs of THD were estimated by pooled OR in a fixed-effect model. Sedation, constipation, and dizziness/drowsiness were the most common side effects (Table 2). Nevertheless, AEs did not bring about level 3 or 4 toxicity and could be tolerated by patients. No other THD-related AEs were suggested in our analysis. However, the $P$ value (0.06) of peripheral neuropathy should be noted. This complication may be associated with cumulative dosage, emphasizing the requirement of defined recommendations for monitoring, tapering, and discontinuation. Though 18 studies we totally collected specifically targeted on the investigation of THD on CINV, there were no high quality RCTs further comparing THD and some regular drugs such as: NK1-RA, Olanzapine or Dexamethasone recommended in the Guidelines of American Society of Clinical Oncology (ASCO) and National Comprehensive Cancer Network (NCCN)[9]. Well-designed clinical trials between THD and these anti-CINV drugs are required to line THD up to a waitlist for the antiemetic treatment scenario.

THD, as an antiangiogenic agent, has produced substantial clinical benefits in the treatment of multiple myeloma, and its effects on a host of solid tumors have been quite variable. There seems to be a reasonable consensus that THD has demonstrable tumoristatic effects in renal cell carcinoma [49], hepatocellular carcinoma [50,51], prostate carcinoma [52], Kaposi's sarcoma [53], melanoma [54], glioma [55], and glioblastoma multiforme [56]. The main pathophysiological features of advanced cancer are insomnia, chronic emesis, nausea, cachexia, metabolic disorders, and tumor-associated pain as well as decreased sensation of wellbeing. Perhaps the most 
intriguing quality of THD is its underlying value in many of these syndromes, as demonstrated in our analysis, and the fact that it is well tolerated in this very ill patient population in general. Emotional disturbance is quite usual after cancer diagnosis, and it could adversely affect treatment, sleep, and appetite. We observed that THD enhanced the CR of CINV as well as improved the diet and sleep of patients compared to those on a non-THD regimen [20]. Bruera et al. [45] reported a significant increase in caloric intake for 27 patients who were able to complete their food intake, from 1320 calories on day 0 to 1531 calories on day $10(P=0.047)$. In the THD group, $93 \%$ of patients hoped to take THD again in the next cycle of chemotherapy. Better chemotherapy compliance was noted in the THD group. The latent role of THD within the field of palliative treatment thus requires further investigation.

Elucidation of the heterogeneity of the effect in the delayed vomiting phase is critical to inform an individualized therapy and precision medicine approach, one that encompasses chemotherapy and patients' characteristics to guide targeted THD prescriptions. For example, when CINV patients also develop insomnia, diarrhea, irritability, or hyperactivity, a corresponding dosage of THD may be a more appropriate choice. THD has synergistic and additive antiemetic, anti-asthenia, and analgesic effects of corticosteroids [57, 58]; it inhibits the expression of cytokines without affecting levels of IL-2, IL-4, and IL-10 [59, 60], thus offering the possibility of steroid-sparing or steroid-replacement therapy. Rigorous examination and enforcement of such an approach pose significant challenges to the field but could hold great promise to improve the safety and efficacy of anti-CINV therapy in the clinical environment.

The strengths of our analysis are as follows. First, the pooled studies were all RCTs that enhanced the evidence grade. Second, the control group were all uniformed to blank controls, which eliminated some confounding factors to an extent. Third, we investigated the safety and QOL outcome as we explored the efficacy of THD. However, objective limitations still exist. Firstly, an insufficient number of studies used moderately emetogenic chemotherapy which limited our further investigation of specifying THD's role in moderate and high categories in anti-CINV. Secondly, one study with 638 patients outnumbered other studies in population may cause some inevitable bias. Lastly, all the included patients were Chinese; thus, generalizability of the recommended dosage to other ethnic groups requires caution.

In conclusion, THD is an effective adjunctive treatment to improve $\mathrm{CINV}$ in patients receiving emetic chemotherapy according to our results. Well-designed clinical trials are required to compare the efficacy and safety between THD and NK1-RA or olanzapine to define the place of THD in therapy for the prophylaxis of CINV, to consider the combination of these medicines as the optimum choice, and to assess the AEs systematically. THD is indeed worth considering for prophylactic antiemetic treatment.

\section{Acknowledgements}

We thank all members of our study team for their whole-hearted cooperation and the original authors of the included studies for their wonderful work.

\section{Competing Interests}

The authors have declared that no competing interest exists.

\section{References}

1. Mitchelson F. Pharmacological agents affecting emesis. A review (Part I). Drugs. 1992; 43: 295-315.

2. Leslie RA. Neuroactive substances in the dorsal vagal complex of the medulla oblongata: nucleus of the tractus solitarius, area postrema, and dorsal motor nucleus of the vagus. Neurochem Int. 1985; 7: 191-211.

3. Hesketh PJ. Chemotherapy-induced nausea and vomiting. N Engl J Med. 2008; 358: 2482-94.

4. Bountra C, Gale JD, Gardner CJ, Jordan CC, Kilpatrick GJ, Twissell DJ, et al. Towards understanding the aetiology and pathophysiology of the emetic reflex: novel approaches to antiemetic drugs. Oncology. 1996; 53 Suppl 1: $102-9$

5. Coates A, Abraham S, Kaye SB, Sowerbutts T, Frewin C, Fox RM, et al. On the receiving end--patient perception of the side-effects of cancer chemotherapy. European journal of cancer \& clinical oncology. 1983; 19: 203-8.

6. Navari RM. Management of Chemotherapy-Induced Nausea and Vomiting in Pediatric Patients. Paediatric drugs. 2017; 19: 213-22.

7. Wood DE, Kazerooni EA, Baum SL, Eapen GA, Ettinger DS, Hou LF, et al. Lung Cancer Screening, Version 3.2018. Journal of the National Comprehensive Cancer Network. 2018; 16: 412-41.

8. Hesketh PJ, Kris MG, Basch E, Bohlke K, Barbour SY, Clark-Snow RA, et al. Antiemetics: American Society of Clinical Oncology Clinical Practice Guideline Update. J Clin Oncol. 2017; 35: 3240-61.

9. Natale JJ. Overview of the prevention and management of CINV. The American journal of managed care. 2018; 24: S391-s7.

10. Han ZX, Xu J, Wang HM, Ma J, Sun X, Du XP. Antiemetic role of thalidomide in a rat model of cisplatin-induced emesis. Cell Biochem Biophys. 2014; 70: $361-5$

11. Liu Y, Zhang J, Teng Y, Zhang L, Yu P, Jin B, et al. Thalidomide improves prevention of chemotherapy-induced gastrointestinal side effects following a modified FOLFOX7 regimen: results of a prospective randomized crossover study. Tumori J. 2009; 95: 691-6.

12. Lu G, Pan Y, Yu Z, Zhou X, Yuan H. Mechanisms of Thalidomide combined with Epirubicin on the anti-SMMC7721 proliferation. The Journal of Practical Medicine. 2010; 26: 1038-40.

13. Zustovich F, Cartei G, Ceravolo R, Zovato S, Della Puppa A, Pastorelli D, et al. A phase I study of cisplatin, temozolomide and thalidomide in patients with malignant brain tumors. Anticancer research. 2007; 27: 1019-24.

14. Luo Q. The therapeutic Effect of Thalidomide for advanced NSCLC under GP regimen The Journal of Practical Medicine. 2011; 27: 1080-2.

15. Downs LS, Jr., Judson PL, Argenta PA, Ghebre R, Geller MA, Bliss RL, et al. A prospective randomized trial of thalidomide with topotecan compared with topotecan alone in women with recurrent epithelial ovarian carcinoma. Cancer. 2008; 112: 331-9.

16. Dowlati A, Subbiah S, Cooney M, Rutherford K, Mekhail T, Fu P, et al. Phase II trial of thalidomide as maintenance therapy for extensive stage small cell lung cancer after response to chemotherapy. Lung cancer (Amsterdam, Netherlands). 2007; 56: 377-81.

17. Chiou HE, Wang TE, Wang YY, Liu HW. Efficacy and safety of thalidomide in patients with hepatocellular carcinoma. World journal of gastroenterology. 2006; 12: 6955-60. 
18. Davis M, Lasheen W, Walsh D, Mahmoud F, Bicanovsky L, Lagman R. A Phase II dose titration study of thalidomide for cancer-associated anorexia. Journal of pain and symptom management. 2012; 43: 78-86.

19. Higgins JPT TJ, Chandler J, Cumpston M, Li T, Page MJ, Welch VA (editors). Cochrane Handbook for Systematic Reviews of Interventions version 6.0 (updated July 2019). Cochrane, 2019.

20. Zhang L, Qu X, Teng Y, Shi J, Yu P, Sun T, et al. Efficacy of Thalidomide in Preventing Delayed Nausea and Vomiting Induced by Highly Emetogenic Chemotherapy: A Randomized, Multicenter, Double-Blind, Placebo-Controlled Phase III Trial (CLOG1302 study). Journal of Clinical Oncology. 2017; 35: 3558-+.

21. Jing Z, Hong-gang K, Bao-zhong W, Gui-ming SUN. Clinical research of Palonosetron with Thalidomide for the prophylaxis of nausea and vomiting induced by Lung Cancer. The Journal of Chinese Cancer Clinic and Rehabilitation. 2016; 23: 943-6.

22. Song G, He Q, Li F, Wang N. Thalidomide for prevention of chemotherapy-induced nausea and vomiting following highly emetogenic chemotherapy. Australasian Medical Journal. 2017; 10: 192-8.

23. Jiang H. Clinical Research of Thalidomide for the Prophlaxis of nausea and vomiting induced by Highly Emetic Chemotherapy [post graduate]: China Medical University; 2017.

24. Han Z, Sun X, Xu J, Li Y, Du X. Clinical Research of Thalidomide for Perichemotherapy Induced Nausea and Vomiting. Cancer Research and Clinic. 2014; 26: 667-9.

25. Han Z, Sun X, Jiang G, Du X. Thalidomide for Control Delayed Vomiting in Cancer Patients Receiving Chemotherapy. Journal of the College of Physicians and Surgeons--Pakistan : JCPSP. 2016; 26: 900-3.

26. Cao Y. Therapeutic effect of Thalidomide for Chemotherapy Induced Nausea and Vomiting. Journal of China Prescription Drug. 2017; 15: 72-3.

27. Addressing Reporting Biases. Cochrane Handbook for Systematic Reviews of Interventions. p. 297-333.

28. Poole C, Greenland S. Random-effects meta-analyses are not always conservative. Am J Epidemiol. 1999; 150: 469-75.

29. Higgins JP, Thompson SG, Deeks JJ, Altman DG. Measuring inconsistency in meta-analyses. Bmj. 2003; 327: 557-60.

30. Ioannidis JP, Trikalinos TA. The appropriateness of asymmetry tests for publication bias in meta-analyses: a large survey. Cmaj. 2007; 176: 1091-6.

31. Egger M, Davey Smith G, Schneider M, Minder C. Bias in meta-analysis detected by a simple, graphical test. Bmj. 1997; 315: 629-34.

32. Deeks JJ, Macaskill P, Irwig L. The performance of tests of publication bias and other sample size effects in systematic reviews of diagnostic test accuracy was assessed. J Clin Epidemiol. 2005; 58: 882-93.

33. Copas J, Shi JQ. Meta-analysis, funnel plots and sensitivity analysis. Biostatistics. 2000; 1: 247-62.

34. Duval S, Tweedie R. Trim and fill: A simple funnel-plot-based method of testing and adjusting for publication bias in meta-analysis. Biometrics. 2000; 56: 455-63.

35. Rosenthal R. The file drawer problem and tolerance for null results. Psychological Bulletin. 1979; 86: 638-41.

36. Zuo C. Therapeutic Effect of Thalidomide combining Tropisetron hydrochloride for Metastatic breast cancer Induced Nausea and Vomiting under GP regimen. Chinese Journal of Clinical Research. 2014; 27: 1491-3.

37. Yu Y, Zhu Z, Li J. Therapeutic Effect of Thalidomide for the Prevention of delayed nausea and vomiting induced by NSCLC under GP regimen. Chinese Journal of Oncology. 2009; 31: 937-40.

38. Li M, Gao E, Cui F, Chen L, Zhang F. Clinical Research of Thalidomide combining Ondansetron for the Prophylaxis of Chemotherapy Induced Nausea and Vomiting of Lung Cancer. Journal of Modern Oncology. 2016; 24: 2719-23.

39. Chen Y, Luo D, Wang M. Clinical Research of Thalidomide for the Prevention of Chemotherapy Induced Nausea and Vomiting. Modern Prevention Medicine. 2013; 40: 382-3.

40. Cao Y, Ren J. Analysis of Therapeutic Effect of Thalidomide for the Prevention of Chemotherapy Induced Nausea and Vomiting. The Journal of Chinese and Foreign Medicine. 2017; 36: 132-4.

41. Wang S. Thalidomide combining Palonosetron for the Prevention of Cisplatin-contained Chemotherapy Induced Nausea and Vomiting. Guideline of China Medicine. 2018; 16: 24-5.

42. She M-j, Ma Z-s, Li G-z, Wang Q, Shen Y-l. A Randomized Clinical Study on Combination of Concurrent Chemo-Radiotherapy and Thalidomide for Middle-Late Esophageal Cancer. Clinical Oncology and Cancer Research. 2010; 7: 140-5.

43. Peng Y, Wang M, Xie N, Li Y, Lu H, Li B. Randomized study of thalidomide in combination with TP chemotherapy for the treatment of advanced non-small-cell lung cancer. Chinese Journal of Clinical Pharmacology and Therapeutics. 2013; 18: 317-21.

44. Zhao Y, Sun J, Zhou Q. Effect of thalidomide in Improving Chemotherapeutic patients' Appetites and Life Quality with Lung Cancer. Journal of Mathematical Medicine. 2017; 30: 890-1.

45. Bruera E, Neumann CM, Pituskin E, Calder K, Ball G, Hanson J. Thalidomide in patients with cachexia due to terminal cancer: preliminary report. Annals of oncology : official journal of the European Society for Medical Oncology. 1999; 10: 857-9.
46. Zhu Z, Li J, Gao Q. Clinical Research of Thalidomide Preventing Cisplatin-contained Chemotherapy Induced Delayed Nausea and Vomiting. Journal Of China Pharmacy. 2010; 21: 2464-6.

47. Wang Y, Tang H, Liu N. Clinical Obeservation of Thalidomide In the Prevention of Chemotherapy Induced Delayed Nausea and Vomiting. China Practical Medicine. 2012; 7: 147-8.

48. Cui Y, Li J, Wang W. Effect of Thalidomide combining Tropisetron for Adjuvant Chemotherapy Induced Vomiting of Breast Cancer. The Journal of Practical Medicine. 2011; 27: 3576-8.

49. Amato RJ. Thalidomide therapy for renal cell carcinoma. Critical reviews in oncology/hematology. 2003; 46 Suppl: S59-65.

50. Patt YZ, Hassan MM, Lozano RD, Nooka AK, Schnirer, II, Zeldis JB, et al. Thalidomide in the treatment of patients with hepatocellular carcinoma: a phase II trial. Cancer. 2005; 103: 749-55.

51. Cao DD, Xu HL, Liu L, Zheng YF, Gao SF, Xu XM, et al. Thalidomide combined with transcatheter artierial chemoembolzation for primary hepatocellular carcinoma: a systematic review and meta-analysis. Oncotarget. 2017; 8: 44976-93.

52. Figg WD, Dahut W, Duray P, Hamilton M, Tompkins A, Steinberg SM, et al. A randomized phase II trial of thalidomide, an angiogenesis inhibitor, in patients with androgen-independent prostate cancer. Clinical cancer research : an official journal of the American Association for Cancer Research. 2001; 7: 1888-93.

53. Little RF, Wyvill KM, Pluda JM, Welles L, Marshall V, Figg WD, et al. Activity of thalidomide in AIDS-related Kaposi's sarcoma. J Clin Oncol. 2000; 18: 2593-602.

54. Reiriz AB, Richter MF, Fernandes S, Cancela AI, Costa TD, Di Leone LP, et al. Phase II study of thalidomide in patients with metastatic malignant melanoma. Melanoma research. 2004; 14: 527-31.

55. Pawlak WZ, Legha SS. Phase II study of thalidomide in patients with metastatic melanoma. Melanoma research. 2004; 14: 57-62.

56. Morabito A, Fanelli M, Carillio G, Gattuso D, Sarmiento R, Gasparini G. Thalidomide prolongs disease stabilization after conventional therapy in patients with recurrent glioblastoma. Oncology reports. 2004; 11: 93-5.

57. Moertel CG, Schutt AJ, Reitemeier RJ, Hahn RG. Corticosteroid therapy of preterminal gastrointestinal cancer. Cancer. 1974; 33: 1607-9.

58. Bruera ED, Roca E, Cedaro L, Chacon R, Estevez R. Improved control of chemotherapy-induced emesis by the addition of dexamethasone to metoclopramide in patients resistant to metoclopramide. Cancer Treat Rep. 1983; 67: 381-3.

59. Rowland TL, McHugh SM, Deighton J, Dearman RJ, Ewan PW, Kimber I. Differential regulation by thalidomide and dexamethasone of cytokine expression in human peripheral blood mononuclear cells. Immunopharmacology. 1998; 40: 11-20.

60. Moller DR, Wysocka M, Greenlee BM, Ma X, Wahl L, Flockhart DA, et al. Inhibition of IL-12 production by thalidomide. J Immunol. 1997; 159: 5157-61. 